\title{
The Effect of Water Temperature on Argulus foliaceus L. 1758 (Crustacea; Branchiura) on Different Fish Species
}

\author{
Mustafa KOYUN \\ Bingol University, Science and Art Faculty, Department of Biology-Zoology, 12000 Bingol, Turkey; mustafakoyun16@yahoo.com
}

\begin{abstract}
Parasites belonging to Argulus genus, known as fish louse (Argulus foliaceus L.) significantly affect in negative way both in natural and farming environment. In this study, the pathogenic effect of fish louse temperature on fish depending on water was investigated. In this research to estimate the effects of several factors such as water temperature, gender of the fish and the infection of fish louse were studied through Poisson regression method. As fish species, Alburnus alburnus (bleak), Carassius carassius (crucian carp) and Carassius auratus (golden carp) were caught periodically, starting from May during the year, and the parasites were counted. The gender and metrical measures of the examined fish were categorized separately. The degrees of water temperature of the dam were measured. Results from Poisson regression analysis showed that fish louse has harmful effect on the mentioned fish, depending on the water temperature.
\end{abstract}

Keywords: Argulus foliaceus, Carassius carassius, Carassius auratus, Poisson regression

\section{Introduction}

Recent discoveries of new species and genotypes emphasize the need for more basic researches on louse taxonomy and host preferences. Louse development rates are strongly dependent on temperature, while increasing water temperatures mean is likely to increase infestation pressure on farm and wild fish. This knowledge could be used to take precaution to reduce the risks of lice affecting farmed and wild fish (Costello, 2006). Fish lice of the genus Argulus are ectoparasites known from Europe, Central Asia and the USA (Yamaguti, 1963). The ectoparasitic crustacean $A$. foliaceus $\mathrm{L}$. is frequently found on different species of freshwater fish. Many diseases in fish prevent productivity and fertility due to harmful effects. One of the most important factors that prevents fish growth and causes lost in yields is $A$. foliaceus L., known as fish lice. It is an obligatory blood sucker and can survive for only a few days without the host fish, depending on its size and ambient temperature (Kollatsch,1959). A. foliaceus is widespread in Turkey and it is likely that it occurs all over the country (Oktener et al., 2010).

During the summer, fish are heavily infected and very disturbed by the intense attacks of parasites because of their very hemorrhagic skin. Especially small parasites occur on almost all parts of the skin and fins, with slightly heavier concentrations on and around the pectoral and pelvic fins. Large parasites are found mainly on the skin around these fins (Pasternak et al., 2000). In this study, according to datum, male fish were more heavily infected than female on bleak, but on crucian carp and golden carp are nearly equal. These cases are discussed in the context of risks and rewards.
Previous studies reported that measurements cannot be always obtained as continuous data. These measurements are obtained in some cases by enumeration. Some of the measurements from the enumerations such as examined fish number, infected fish number, temperature, counting parasite number etc. show the Poisson distribution. Counting the data of any event occurring within a specific period is defined as a number. It is considered that counting the data consisting of variables can be analyzed with the linear regression model. However, when linear regression model is applied to count the data, unreliable results may be obtained (Ankarali et al., 2005).

Poisson regression model for the analysis of counted data is considered as a starting point (Akin, 2000). Maximum likelihood estimation is used instead of the least squares method (Cameron and Trivedi, 1986; Hendrickx, 2002; Deniz, 2005).

Fish lice, which cause damage on fish, are affected at different times by the impact of environmental factors and their effects increase or decrease the negative impact. The data obtained from studies of fish are usually discrete data. These data are consistent with the Poisson distribution.

When Mc Conell et al. (1995) measured the number of fish lice because of the Poisson distribution, they applied linear regression model in the weak and inconsistent results, which may be conflicting. Therefore, Poisson regression model was applied afterwards. This study aimed to determine the effects of temperature on the presence of A. foliaceus L. by using Poisson regression. 


\section{Materials and methods}

\section{Fish sampling}

The fish samples were regularly monitored from the beginning of May and the parasites were encountered monthly. The measurements of each fish species were evaluated separately as males and females. While making the measurements, at the same time, water temperatures of Enne Dam Lake were also measured; counting process once in a month intervals were done during 9 months in total. The damage of the parasite to the fish species was noted to determine the density of fish.

\section{Parasite collection}

The total number of parasites collected from the fish was recorded during the year from May to January. The external surfaces, buccal and gill cavities of all fish were examined thoroughly for Argulus individuals, which were subsequently removed carefully using a set of blunt forceps. The analyzed data were grouped according to the gender of fish parasites. Parasites were stored with $70 \%$ alcohol, for use in subsequent studies.

\section{Statistical analyses}

The results obtained were analyzed with Poisson regression analysis.

Poisson regression model can be written as follows:

$$
\frac{c}{N}=e^{\alpha+\beta_{i} x_{i}+\varepsilon_{i}}
$$

c: The number of fish that suffered the effects of interference, $\quad \mathrm{N}$ : Number of total examined fish,

$\alpha$ : Fixed term

$\beta_{i}$ : Regression coefficient of the explanatory variable (temperature),
$\mathrm{x}_{\mathrm{i}}$ : Explanatory variables,
$\varepsilon$ : Error term
e: 2.1718 (natural logarithm base) respectively.

A variety of goodness fit tests are conducted to the results of the analysis. These can be explained as follows (Dobson, 2002; Ozmen, 2003; Deniz, 2005):

1. Statistics: $\mu_{\mathrm{i}}$ the average and $\mathrm{w}_{\mathrm{i}}$ variance dependent variable belongs $\mathrm{y}_{\mathrm{i}}$ to standard

$$
\text { As } P=\sum_{i=1}^{n} \frac{\left(\begin{array}{ll}
y_{i} & \hat{\mu}_{i}
\end{array}\right)}{\hat{w}_{i}}
$$

This value of the series is used to determine whether excess emission. Where $\hat{\mu}_{i}$ and $\hat{w}_{i}$ values, are the values of the estimation. Calculated $\mathrm{P}$ value is compared with the degree of freedom that is determined for $w_{i}=\mu_{i}(\mathrm{n}-\mathrm{k})$. This formula is applied to the Poisson, and $P_{p}=\sum_{i=1}^{n} \frac{\left(y_{i}\right.}{\left.\hat{\mu}_{i}\right)^{2}}$ will take shape.

The value of $P p$ calculated is similarly $(\mathrm{n}-\mathrm{k})$ compared with the value.
Here,

$\mathrm{P}>\mathrm{n}-\mathrm{k}$ overdispersion in the series,

2. Another technique used to measure the accordance of fit statistics is deviation statistics.

The value of these statistics is also called 'square statistic G'.

Square statistic G; $G^{2}=2 \sum_{i=1}^{n} y_{i} \ln \left(\frac{y_{i}}{\mu_{i}}\right) \quad$ is expressed
the form.

These statistics will converge to 0 and that will increase the compliance of the model. If this statistic is exactly 0 , it is a perfect fit in the model.

3. $\mathrm{R}^{2}$ is an artificial measurement: the use of the nonlinear model does not have a common definition of $R^{2}$.

Because of these uncertainties, the calculated value is expressed by 'artificial'.

Poisson regression models for the $R_{p}^{2}$ measure:

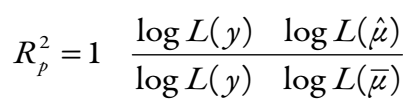

as defined. Where the log-likelihood function:

$$
\begin{array}{lll}
\log L(y)=\sum_{i=1}^{n}\left(y_{i} \log \left(y_{i}\right)\right. & y_{i} & \left.\log \left(y_{i} !\right)\right) \\
\log L(\hat{\mu})=\sum_{i=1}^{n} y_{i} \log \left(\hat{\mu}_{i}\right) & \hat{\mu}_{i} & \left.\log \left(y_{i} !\right)\right) \\
\log L(\bar{y})=\sum_{i=1}^{n}\left(y_{i} \log \left(\bar{y}_{i}\right)\right. & \bar{y}_{i} & \left.\log \left(y_{i} !\right)\right)
\end{array}
$$

forms are obtained. The log-likelihood function is regulated, artificial $\mathrm{R}^{2}$ measure is obtained.

\section{Accordance of fit chi-square test}

Established to examine the accordance of fit; hypothesis is as follows:

$\mathrm{H}_{0}$ : Data fit for Poisson regression model

$\mathrm{H}_{1}$ : Data disobey for Poisson regression model

Pearson $\chi^{2}$ statistics; is calculated with this equation:

$$
\chi^{2}=\sum_{i=1}^{j} \frac{\left(n \bar{p}_{j} \quad n \hat{p}_{j}\right)^{2}}{n \hat{p}_{j}}
$$

Observed frequencies, where, $n \bar{p}_{j}, n \hat{p}_{j}$ represent the theoretical frequencies. The results of these equations are given with the help of $(\mathrm{N}-\mathrm{p})$ degrees of freedom compared to a value of $\chi^{2}$. The number of units of $\mathrm{N}, \mathrm{P}$ is the estimated number of parameters to be desired. If the calculated value exceeds the value of $\chi_{N}^{2} p$ it is rejected and the hypothesis is assumed to fit the Poisson model. In the case of being smaller, the average variance shows overdispersion. In these cases, Poisson regression cannot be utilized. Instead of this, regression analyses containing dispersion parameter explaining extra Poisson change are used. These regression analyses are negative binomial regression, mixed Poisson regression and mutual Poisson regression analyses. 
18

\section{Results and discussion}

In the present study, the quantity of fish analyzed according to the species and the quantity of parasites, determined according to the gender and water temperatures, are shown in Tab. 1 . As illustrated in Tab. 1, it is seen that fish louse has no effect no matter what gender the fish species are in May. Similar effect is also seen in January. Fish lice start to be ectodoparasite and increase rapidly depending on the water temperature in June. A high level of correlation between the water temperature and fish lice was estimated; August and September were the peak months of the louse population. mated as shown in Tab. 2. As seen in Tab. 2, the effect of temperature on the amount of parasites on fish species has been determined in different proportions reflected in the equation.

Temperature rise has effect mostly on bleak. According to the estimation, in the case of temperature rise, the quantity of fish louse will increase too. When Carassius species were examined, temperature effect was realized in the regression equation from Poisson regression analysis.

The higher the temperature gets, the higher the quantity of fish louse giving harm to the fish occurs. But the quantity is not as high as in $A$. alburnus. It is known that fish louse ( $A$. foliaceus), regarded as ectoparasites of sea and

Tab. 1. The quantity of parasite seen according to the gender of the fish species and water temperature

\begin{tabular}{|c|c|c|c|c|c|c|c|}
\hline \multirow{3}{*}{ Time } & \multirow{2}{*}{\multicolumn{2}{|c|}{$\begin{array}{c}A \text {. alburnus } \\
\text { Parasite quantity }\end{array}$}} & \multirow{2}{*}{\multicolumn{2}{|c|}{$\begin{array}{c}\text { C. carassius } \\
\text { Parasite quantity }\end{array}$}} & \multirow{2}{*}{\multicolumn{2}{|c|}{$\begin{array}{c}\text { C. auratus } \\
\text { Parasite quantity }\end{array}$}} & \multirow{3}{*}{$\begin{array}{c}\text { Water } \\
\text { temperature }\end{array}$} \\
\hline & & & & & & & \\
\hline & Female & Male & Female & Male & Female & Male & \\
\hline May & - & - & - & - & - & - & 14.0 \\
\hline June & 6 & 3 & - & - & - & - & 18.5 \\
\hline July & 5 & 5 & 3 & 3 & 2 & 3 & 23.0 \\
\hline August & 42 & 60 & 15 & 10 & 12 & 13 & 26.0 \\
\hline September & 65 & 86 & 10 & 7 & 9 & 8 & 22.0 \\
\hline October & 22 & 18 & 10 & 7 & 9 & 8 & 19.0 \\
\hline November & 2 & 3 & - & 2 & 1 & 2 & 16.0 \\
\hline December & - & 2 & 1 & 1 & 2 & - & 10.0 \\
\hline January & - & - & - & - & - & - & 8.5 \\
\hline Total & 142 & 177 & 39 & 34 & 38 & 35 & $\bar{x}=17,4$ \\
\hline
\end{tabular}

Regarding the quantity of parasite according to gender, $A$. alburnus male fish are affected more, while Carassius male are affected less compared to the female fish. According to this, it can be said that parasite formation changes dramatically with regard to fish species and genders (Kir,1998; Kutlu and Ozturk, 2006).

When results of Poisson regression analysis were taken into consideration, the regression equations were esti-

Tab. 2. Regression equations obtained from Poisson regression analysis

\begin{tabular}{|c|c|c|}
\hline Species & Gender & Equations \\
\hline \multirow{2}{*}{ A. alburnus } & Female & $\begin{array}{c}\text { NFL } / \text { TNF }=\operatorname{Exp} \\
(68.87+1.7649 \text { temperature })\end{array}$ \\
\hline & Male & $\begin{array}{c}\text { NFL } / \text { TNF }=\text { Exp } \\
(72.14+2.2403 \text { temperature })\end{array}$ \\
\hline \multirow{2}{*}{ C. carassius } & Female & $\begin{array}{c}\text { NFL } / \text { TNF }=\text { Exp } \\
(47.68+0.7562 \text { temperature })\end{array}$ \\
\hline & Male & $\begin{array}{c}\text { NFL } / \text { TNF }=\text { Exp } \\
(48.87+0.8714 \text { temperature })\end{array}$ \\
\hline \multirow{2}{*}{ C. auratus } & Female & $\begin{array}{c}\text { NFL } / \text { TNF }=\text { Exp } \\
(51.27+0.3247 \text { temperature })\end{array}$ \\
\hline & Male & $\begin{array}{c}\text { NFL } / \text { TNF }=\text { Exp } \\
(52.21+0.5421 \text { temperature })\end{array}$ \\
\hline \multicolumn{3}{|c|}{$\begin{array}{l}\text { NFL: The quantity of fish louse, TNF: Total number of fish } \\
\text { Exp: Natural logarithm base (2.71828) }\end{array}$} \\
\hline
\end{tabular}

freshwater fish does considerable harm to fish worldwide. Since they live on sucking the fish blood and other tissue fluid and also act as conveyer to secondary infection factors, they endanger their hosts. After perforating the host's skin, fish louse drains the substance secreted beforehand into the wound and sucks the blood from the blood vessel it has perforated. Temperature has trigger effect on this harm. Because the higher the temperature gets, the more parasites come over the fish, and the amount of harm can be more than it is expected.

When Tab. 3 is analyzed, it is deduced that each fish species has not dispersed overly in terms of Pearson statistics. When analyzed in terms of deviation statistics $\left(\mathrm{G}^{2}\right)$, $A$. alburnus has the highest fit with 8.24 , followed by $C$. carassius with 9.36 and $C$. auratus with 10.69 . When studied in terms of artificial $\mathrm{R}^{2}$, while the highest $\mathrm{R}^{2}$, was seen in $C$. carassius species with 81.23 , the lowest $\mathrm{R}^{2}$ is seen in C. auratus species with 71.74. When assessed according to the gender, it is seen that in Pearson and deviation statistics, $A$. alburnus and $C$. auratus species' males have higher figures than females. But in $C$. auratus species, females have higher figures than males. In terms of artificial $\mathrm{R}^{2}$ in these species, it shows just the opposite features compared to the previous ones. By these results, goodness of fit figures differs according to the species. It is anticipated that these changes have derived from physiological and morphologi- 
Tab. 3. Poisson regression analysis, goodness of fit evaluation results

\begin{tabular}{ccccccc}
\hline \multirow{2}{*}{ Goodness of fit criteria } & \multicolumn{4}{c}{ Fish species } \\
\cline { 2 - 7 } & \multicolumn{2}{c}{ A. alburnus } & \multicolumn{2}{c}{ C. carassius } & \multicolumn{2}{c}{ C. auratus } \\
\cline { 2 - 7 } & Female & Male & Female & Male & Female & Male \\
\hline Pearson statistic & 8.24 & 9.01 & 10.47 & 9.68 & 12.38 & 13.08 \\
Deviation statistic & 8.45 & 8.63 & 9.36 & 9.21 & 10.27 & 10.69 \\
Artificial R & 75.40 & 69.12 & 81.23 & 84.51 & 72.36 & 71.74 \\
Chi-square & 24.02 & 23.68 & 21.16 & 20.63 & 29.68 & 30.57 \\
\hline
\end{tabular}

cal features of the fish. The study examined chi-square statistics for hypothesis $\mathrm{H}_{0}$ was not accepted. This indicator is considered to be inadequate in alignment with the model. However, to be compatible in terms of other characters, it is understood to be compatible with the overall model.

\section{Conclusions}

The present study gave the average figures and variance of fish louse giving harm to fish in Poisson regression model. Besides this, in real data, variance is found out more than the average.

These results come across if there are many zeros in the data. According to the data obtained at the end of the study, it has been deduced there is too much emission. While some researchers state that this emission figure can be ignored (Wang et al., 1996; 1998), others state that it should be analyzed even if it is close to one (Ozmen, 2000; Dalrymple et al., 2002; Yeşilova, 2003).

But he ascertained that the more the quantity of subpopulation gets, the bigger the fit criterion figures are. Based on this, in this study, separation process for subgroups has not been carried out, considering the goodness of fit figures will rise.

As a result, it was concluded that temperature has a significant effect on fish louse quantity giving harm to fish.

\section{References}

Akin F (2000). Quantitative analysis of preference models. Ekim Bookstore. Bursa, Turkey.

Ankarali H, Mendeş M, Akkuş Z, Erden S, Erdoğan S, Keskin S, Toros F (2005). Suicide in children living in Mersin Poisson Regression model for frequency of Use. VIII. Biostatistics National Congress, Bursa, Turkey.

Cameron C, Trivedi P (1986). Regression analysis of count data. Cambridge University Pres.

Costello MJ (2006). Ecology of sea lice parasitic on farmed and wild fish. Trends in Parasitology 22(10):475-483.

Dalrymple ML, Hudson IL, RPK Ford (2002). Finite miture zero-inflated Poisson and Hurdle models with application to SIDV. Comput Statist Data Analysis 41(3-4):491-504.

Dobson A (2002). An introduction to Generalized Linear Models, second Edn, Chapman and Hall/CRC, USA.

Deniz O (2005). Poisson regression analysis. Journal of Commerce 4(7):59-72.
Hendrickx J (2002). Review of Regression models for categorical dependent variables using stata by long and freese. The Stata Journal 2(1):103-105.

Kollatsch D (1959). Untersuchungen über die biologie und ökologie der karpfenlaus (Argulus foliaceus L.). Zool Beitr 5:1-36.

Kir I (1998). Investigation of parasites of carp (Cyprinus carpio L., 1758) and barbus (Barbus capito pectoralis L., 1758) living in Karacaören Dam Lake. PhD Thesis, S. Demirel University, Institute of Science, Isparta, Turkey.

Kutlu HL, Ozturk MO (2006). Metazoan parasites of Cyprinus carpio from Lake Karamik (Afyonkarahisar) on anatomical, morphological and ecological research. Journal of Fisheries 23(3-4):389-393.

Mc Conell KE, Strand IE, Blake-Hedegs L (1995). Random utility models of recreational fishing: Cathing Fish Using a Poisson Process. Arine Resourches Economics 10:247-261.

Oktener A, Alaş A, Solak K (2010). Findings of fish lice, Argulus foliaceus (Crustacea; Branchiura) in Turkey. Electronic Journal of Ichthyology 1:9-14.

Ozmen I (2000). Quasi Likelihood/Moment Method for generalized and restricted Poisson Regression models and its application. Biometrical Journal 42(3):300-314.

Ozmen I (2003). Poisson Regression model coefficients for Adjusted Markup. Antalya Statistics Congress 75-79.

Pasternak AF, Mikheev VN, Valtonen ET (2000). Life history characteristics of Argulus foliaceus L. (Crustacea: Branchiura) populations in Central Finland. Ann Zool Fenn 37:25-35.

Sonmez SN (1996). Investigation of parasitic fauna of fishes in Mogan Lake. Masters Thesis, Ankara University, Institute of Science, Ankara, Turkey.

Wang P, Puterman ML, Cockburn IM, Le N(1996). Mixed Poisson Regression Models I $^{\text {th }}$ covariate dependent rates. Biometrics 52:381-400.

Wang P, Cockburn IM, Puterman ML (1998). Analysis of patent data-mixed Poisson Regression Model approach. Journal of Business and Economic Statistics 16(1):27-41.

Yamaguti S (1963). Parasitic Copepoda and Branchiuran of fishes. Inter science Publications at New York, US.

Yeşilova A (2003). Obtained from the study of biological categorical data Analysis application of Mixed Poisson Regression. Phd Thesis. YYU. Institute of Science, Turkey. 